\title{
Processing of granules based on peat and sludge
}

\author{
Zhanna Petrova, Yuliia Novikova, Anton Petrov \\ Department of Heat and mass transfer in heat technologies, Institute of Engineering Thermophysics of NAS of \\ Ukraine, Ukraine, Kyiv, 2, Bulakhovsky 2 Str., E-mail: bergelzhanna@ukr.net
}

\begin{abstract}
The urgent task is to move from traditional energy sources to alternative ones. The purpose of the work is to study the creation and drying of granules based on sludge and peat. The kinetics of drying of granules depending on different compositions and proportions of components is investigated.
\end{abstract}

Keywords - peat, sludge, fuel, granulation, drying.

\section{Introduction}

An urgent problem in Ukraine is the increase in gas and oil prices. The transition from traditional fuels to alternative (renewable) fuels that help the country become energy independent and cover the shortage of traditional fuels. One of the cheap alternative fuels is peat.

On the overflow of sludge sites, activated sludge merges every year, which over the years turns into sludge, which leads to the deterioration of the ecology of Ukraine. These sites store sludge that are more than 30 years old with a low content of organic matter, so they are not suitable for fuel and fertilizers. To increase the organic component to the sludge should be added peat [1].

The purpose of the work is to study the creation and drying of granules based on sludge and peat.

\section{Discussion of results}

On the basis of sludge and peat created different compositions in 3 proportions. In compositions 1 and 2 , sludge of $63.1 \%$, peat with a moisture content of $75.1 \%$ and $45.1 \%$, respectively, were added.

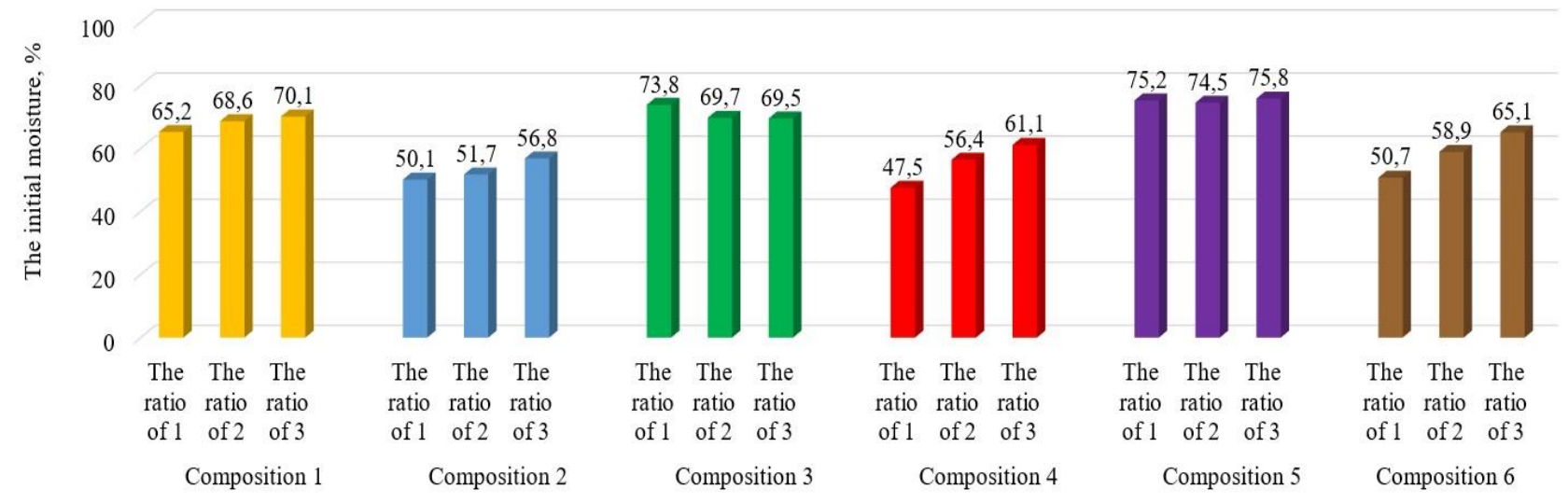

Fig. 1. Variable of initial moisture depending on the composition and the ratio of the composition of the granules.

For composition 3 and 4 -sludge with a moisture content of $70.1 \%$, peat with a moisture content of $75.1 \%$ and $45.1 \%$, respectively. To the composition 5, 6 - sludge with a moisture content of $75.9 \%$, peat with a moisture content of $75.1 \%, 45.1 \%$, respectively. The formed granules with peat with a moisture content of $45.1 \%$ crumbled [2]. 


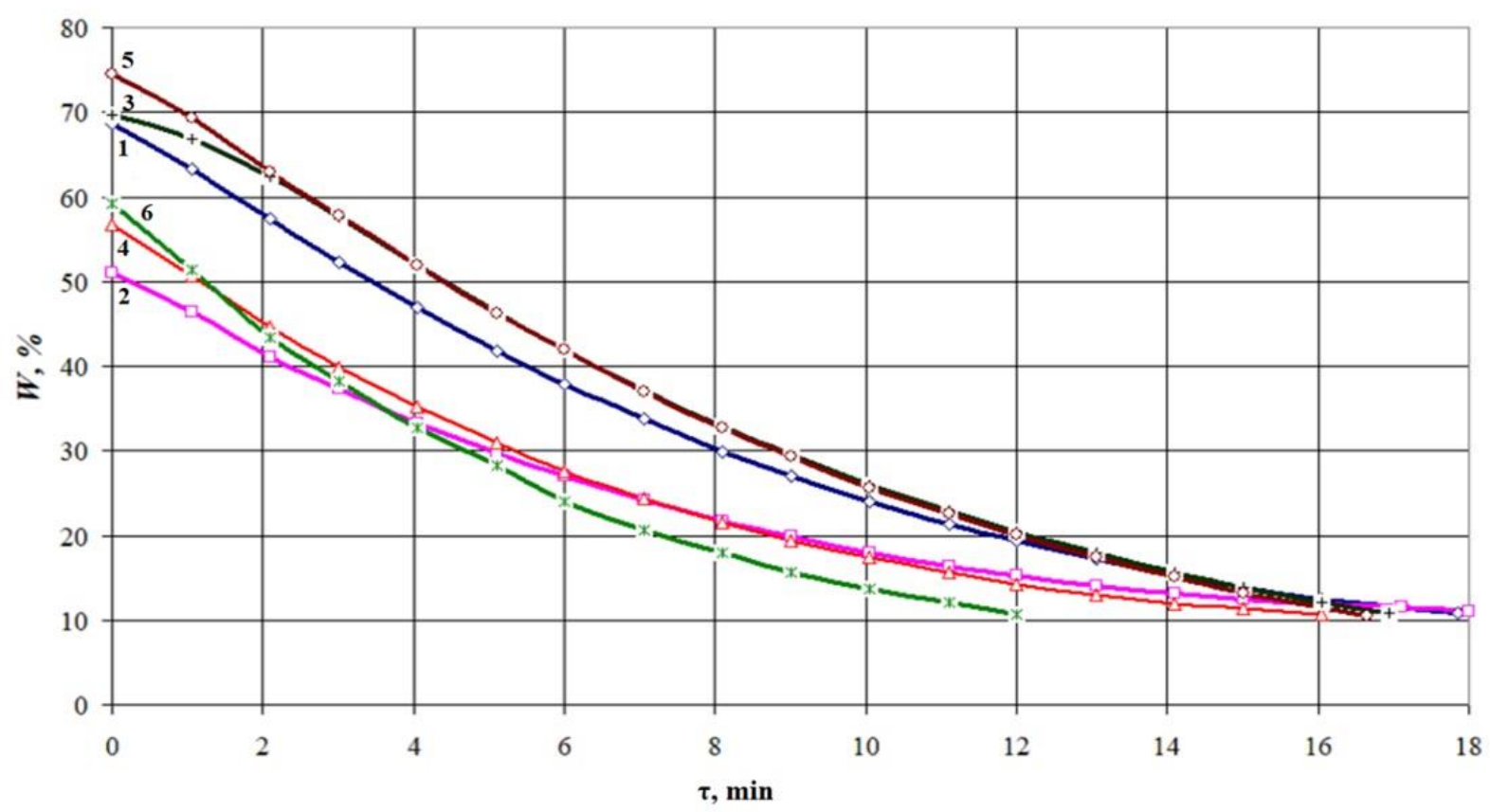

Fig. 2. The effect of the components of the compositions № 1 - 6 on the duration of drying in the second ratio at $\mathrm{t}=120^{\circ} \mathrm{C}, \mathrm{V}=2 \mathrm{~m} / \mathrm{s}, \mathrm{d}=6 \mathrm{~mm}$

In fig. 2. the research of kinetics of drying process from compositions № 1 - 6 in the second ratio of components is represented. As can be seen from the figure, the shortest drying time in composition 6, which is 1.5 times less than in composition 2. In General, the drying time of granules with a diameter of $6 \mathrm{~mm}$ in different compositions at different ratios is 16 to 18 minutes.

\section{Conclusion}

Granules with "burt" peat (moisture 45.1\%) in the ratio 6 has the lowest drying rate, but all the formed granules are brittle and crumble. Therefore, for further work it is advisable to choose the ratio of "fresh" peat (moisture 75.1\%).

\section{References}

[1] Petrova, Zh.O., Kremnov, V.O., Korbut, N.S., \& Novikova Yu.P. (2020). Granulation of mixtures of obsolete sludge and peat. Abstracts of papers XVIII Interenational scientific conference "Improvement of processes and equipment in food and chemical industries" (Oct. 12-16, 2020, Odessa). (pp. 14-16). Odessa: Odessa National Academy of Food Technologies.

[2] Petrova, Zh., \& Novikova, Yu. (2021, March 17). Preparation of raw materials, creation of compositions and granulation from obsolete sludge, peat and biomass. Ceramics: Science and Life, 1(50), 14-18. https://doi.org/10.26909/csl.1.2021.2 